\title{
Underutilization of societal guidelines: occasional or widespread?
}

\section{(ㄷ)(1) $\Theta$}

\author{
Author \\ Richard Kozarek \\ Institution \\ Digestive Disease Institute, Virginia Mason Medical Center, \\ Seattle, Washington, United States \\ Bibliography \\ Endosc Int Open 2021; 09: E986-E988 \\ DOI 10.1055/a-1399-8891 \\ ISSN 2364-3722 \\ (C) 2021. The Author(s). \\ This is an open access article published by Thieme under the terms of the Creative \\ Commons Attribution-NonDerivative-NonCommercial License, permitting copying
}

\author{
and reproduction so long as the original work is given appropriate credit. Contents \\ may not be used for commercial purposes, or adapted, remixed, transformed or \\ built upon. (https://creativecommons.org/licenses/by-nc-nd/4.0/) \\ Georg Thieme Verlag KG, Rüdigerstraße 14, \\ 70469 Stuttgart, Germany \\ Corresponding author \\ Richard Kozarek, MD, Virginia Mason Medical Center, 1100 \\ 9th Avenue, Seattle, WA 98101, USA \\ Fax: +1-206-341-0061 \\ Richard.Kozarek@virginiamason.org
}

The current publication by Issak et al, "Prophylactic rectal indomethacin and pancreatic duct stents (PPS) for prevention of post-ERCP pancreatitis (PEP) are underutilized in average and high-risk patients undergoing ERCP" [1], reviews 31,050 adults captured by the IBM Explorys database between 2014 and 2019. Patients were categorized by risk factors for PEP, which included female sex, age $<40$ years, sphincter of Oddi dysfunction, history of acute pancreatitis, or pancreatic sphincterotomy at time of the procedure [2]. Average-risk patients had no risk factors, and patients were stratified for 0 to $\geq 3$ risk factors. The database did not allow retrieval of other procedural risk factors for PEP to include multiple cannulation attempts, multiple pancreatic duct injections, pancreatic acinarization with contrast injection, or failure to use guidewire cannulation to selectively access the biliary tree; nor did it define the ERCP experience of the endoscopist or whether a trainee was involved in the procedure. The primary outcome of the study was to define the incidence of nonsteroidal anti-inflammatory drug (NSAID) or pancreatic stent use in an attempt to decrease PEP. Secondary outcomes were prophylaxis for and incidence of PEP contingent upon number of risk factors. Not surprising was that as the number of risk factors increased, so too did PEP. What perhaps was surprising in this study was that only one-third of all patients undergoing ERCP received PEP prophylaxis. This included $82.4 \%$ receiving rectal indomethacin and $12.4 \%$ who had placement of a prophylactic pancreatic stent (PPS).

Despite multiple limitations of this study, to include its retrospective review of a database that provides a suboptimal diagnosis of PEP and fails to account for most procedural and endoscopist risk factors, it nevertheless is very clear that endoscopists in this database failed to adhere to societal guide- lines to reduce the risk of PEP in two-thirds of the patients. These include recommendations by the ASGE and ESGE as well as from Japan [3-5].

Given the prospective and randomized controlled trials demonstrating the efficacy of rectal NSAIDs to reduce the risk and severity of PEP in average as well as high-risk patients [6$11]$, these societal guidelines are clear that all patients undergoing ERCP should receive periprocedural rectal NSAIDS. Moreover, although there are no formal societal guidelines that recommend use of PPS, their use has been associated with a decreased risk of PEP in patients undergoing complex ERCP [10]. Such stents were placed in $4.3 \%$ of these patients in this series, and only $1.6 \%$ of these patients had both PPS and rectal indomethacin. Whether this "belt and suspenders" prophylaxis proves more effective than either technique alone to prevent PEP is unknown at the time but is currently undergoing study in the National Institutes of Health-sponsored stent vs indomethacin study (SVI).

So, what good are societal guidelines, most derived from a graded review of the literature, supplemented by expert opinion [12-15], if they are not followed? And is this underutilization occasional or systemic? Furthermore, are there any repercussions of failure to follow them other than the potential for suboptimal patient outcomes? In other words, do they have any teeth such that failure to follow them leads to failure to become privileged in an endoscopy unit or censure of privilege by ignoring one or more specific guidelines? Is there a financial incentive to adhere to guidelines, or is there actually a perverse incentive to overuse certain endoscopic procedures despite guidelines? 
The above are complex issues and perhaps beyond the scope of this editorial.

Guideline adherents point to improved patient outcomes and standardization of care, whereas those who fail to heed them cite contradictory recommendations, the continued evolution of guideline recommendations, and their profusion in all aspects of endoscopic practice leading to "cookbook care." As such, we have evolved practice patterns to ensure compliance with screening and potentially banding cirrhotic patients to prevent an index variceal bleed [16]. We recommend screening of virtually all patients for colorectal cancer and variable surveillance intervals based upon initial findings, genetics, and family history [17-21]. We screen and variably surveille for Barrett's esophagus and undertake or refer patients to experienced colleagues for endoscopic mucosal resection or endoscopic submucosal dissection with finding of high-grade dysplasia and high-risk patients with superficial malignancy [2226]. We recognize that chromo-endoscopy finds more dysplasia with fewer biopsies then white light endoscopy with or without the ability to magnify the image or filter the wavelength, but without formal societal guidelines, it is the minority of endoscopists who utilize it in screening patients with inflammatory bowel disease [27-29]. However, there are guidelines to screen for gastric malignancy [30], to perform and interpret capsule endoscopy [31] appropriately, and about the appropriate application of endoscopic ultrasound [32], as well as dozens of other endoscopic procedures. Not to mention procedural sedation, the appropriate cessation intervals for various anticoagulants and the indications for periprocedural antibiotics.

That brings us back to the Issak et al manuscript in the current issue of Endoscopy International Open [1]. Was failure to treat patients undergoing ERCP with NSAIDs or PSP related to skepticism about the results of previous studies, ignorance of those studies, or as the authors suggest, inadequate access to rectal indomethacin (or skill set to place a PSP)? It is clear, at least in this instance, that underutilization of societal guidelines is widespread and that this failure can be associated with significant iatrogenic patient illness on the one hand and cumulative hospitalization-related expense, on the other. Without definitive consequences for non-adherence, guidelines are just that, guidelines.

\section{Competing interests}

The authors declare that they have no conflict of interest.

\section{References}

[1] Issak A, Elangovan A, Ferguson RD et al. Underutilization of prophylactic rectal indomethacin and pancreatic duct stent for prevention of post-ERCP in average- and high-risk patients. Endosc Int Open 2021; 9: E979-E985

[2] Freeman ML, DiSario JA, Nelson DB et al. Risk factors for post-ERCP pancreatitis: a prospective, multicenter study. Gastrointest Endosc 2001; 54: 425-434
[3] Dumonceau JM, Andriulli A, Elmunzer B] et al. Prophylaxis of postERCP pancreatitis: European Society of Gastrointestinal Endoscopy (ESGE) Guideline - updated June 2014. Endoscopy 2014; 46: 799-815

[4] Chandrasekhara V, Khashab MA. ASGE Standards of Practice Committee. et al. Adverse events associated with ERCP. Gastrointest Endosc 2017; 85: 32-47

[5] Yokoe M, Takada T, Mayumi T et al. Japanese guidelines for the management of acute pancreatitis: Japanese Guidelines 2015. J Hepatobiliary Pancreat Sci 2015; 22: 405-432

[6] Elmunzer B], Scheiman JM, Lehman GA et al. A randomized trial of rectal indomethacin to prevent post-ERCP pancreatitis. N Engl J Med 2012; 366: 1414-1422

[7] HeX, Zheng W, Ding Y et al. Rectal indomethacin is protective against pancreatitis after endoscopic retrograde cholangiopancreatography: systematic review and meta-analysis. Gastroenterol Res Pract 2018; 2018: 9784841

[8] Avila P, Holmes I, Kouanda A et al. Practice patterns of post-ERCP pancreatitis prophylaxis techniques in the United States: a survey of advanced endoscopists. Gastrointest Endosc 2020; 91: 568-73.e2

[9] Yaghoobi M, Alzahrani MA, McNabb-Baltar J et al. Rectal indomethacin prevents moderate to severe post-ERCP pancreatitis and death and should be used before the procedure: a meta-analysis of aggregate subgroup data. J Can Assoc Gastroenterol 2018; 1: 67-75

[10] Phillip V, Pukitis A, Epstein A et al. Pancreatic stenting to prevent post-ERCP pancreatitis: a randomized multicenter trial. Endosc Int Open 2019; 7: E860-E868

[11] Kochar B, Akshintala VS, Afghani E et al. Incidence, severity, and mortality of post-ERCP pancreatitis: a systematic review by using randomized, controlled trials. Gastrointest Endosc 2015; 81: 143149.e9

[12] Rizk MK, Sawhney MS, Cohen J et al. Quality indicators common to all Gl endoscopic procedures. Gastrointest Endosc 2015; 81: 3-16

[13] Rutter MD, Senore C, Bisschops R et al. The European Society of Gastrointestinal Endoscopy Quality Improvement Initiative: developing performance measures. Endoscopy 2016; 48: 81-89

[14] Valori R, Cortas G, de Lange T et al. Performance measures for endoscopy services: A European Society of Gastrointestinal Endoscopy (ESGE) quality improvement initiative. United European Gastroenterol J 2019; 7: 21-44

[15] Beg S, Ragunath K, Wyman A et al. Quality standards in upper gastrointestinal endoscopy: a position statement of the British Society of Gastroenterology (BSG) and Association of Upper Gastrointestinal Surgeons of Great Britain and Ireland (AUGIS). Gut 2017; 66: 18861899

[16] Moodley J, Lopez R, Carey W. Compliance with practice guidelines and risk of a first esophageal variceal hemorrhage in patients with cirrhosis. Clin Gastroenterol Hepatol 2010; 8: 703-708

[17] Johnson MR, Grubber J, Grambow SC et al. Physician Non-adherence to Colonoscopy Interval Guidelines in the Veterans Affairs Healthcare System. Gastroenterology 2015; 149: 938-951

[18] Djinbachian R, Dubé AJ, Durand M et al. Adherence to post-polypectomy surveillance guidelines: a systematic review and meta-analysis. Endoscopy 2019; 51: 673-683

[19] Jain A, Shafer L, Rothenmund $H$ et al. Suboptimal adherence in clinical practice to guidelines recommendation to screen for Lynch syndrome. Dig Dis Sci 2019; 64: 3489-3501

[20] Iskandar H, Yan Y, Elwing J et al. Predictors of poor adherence of US gastroenterologists with colonoscopy screening and surveillance guidelines. Dig Dis Sci 2015; 60: 971-978

[21] Lin OS, Gluck M, Nguyen M et al. Screening patterns in patients with a family history of colorectal cancer often do not adhere to national guidelines. Dig Dis Sci 2013; 58: 1841-1848 
[22] Marques de Sá I, Pereira AD, Sharma P et al. Systematic review of the published guidelines on Barrett's esophagus: should we stress the consensus or the differences? Dis Esophagus 2020: doi:10.1093/ dote/doaa 115

[23] Qumseya B, Sultan S. ASGE Standards of Practice Committee. ASGE guideline on screening and surveillance of Barrett's esophagus. Gastrointest Endosc 2019; 90: 335-359.e2

[24] Wani S, Williams JL, Komanduri S et al. Time trends in adherence to surveillance intervals and biopsy protocol among patients with Barrett's esophagus. Gastroenterology 2020; 158: 770-2.e2

[25] Holmberg D, Ness-Jensen E, Mattsson F et al. Adherence to clinical guidelines for Barrett's esophagus. Scand J Gastroenterol 2019; 54: 945-952

[26] Antony A, Pohanka C, Keogh S et al. Adherence to quality indicators in endoscopic surveillance of Barrett's esophagus and correlation to dysplasia detection rates. Clin Res Hepatol Gastroenterol 2018; 42: 591-596

[27] Alexandersson B, Hamad Y, Andreasson A et al. High-definition chromoendoscopy superior to high-definition white-light endoscopy in surveillance of inflammatory bowel diseases in a randomized trial. Clin Gastroenterol Hepatol 2020; 18: 2101-2107

[28] Kim KO, Chiorean MV. Advanced neoplasia detection using chromoendoscopy and white light colonoscopy for surveillance in patients with inflammatory bowel disease. Intest Res 2020; 18: 438-446

[29] Clarke WT, Feuerstein JD. Colorectal cancer surveillance in inflammatory bowel disease: Practice guidelines and recent developments. World J Gastroenterol 2019; 25: 4148-4157

[30] Gasenko E, Leja M, Polaka I et al. How do international gastric cancer prevention guidelines influence clinical practice globally? Eur J Cancer Prev 2020; 29: 400-407

[31] Rondonotti E, Spada C, Pennazio M et al. Adherence to European Society of Gastrointestinal Endoscopy recommendations of endoscopists performing small bowel capsule endoscopy in Italy. Dig Liver Dis 2019; $51: 818-823$

[32] Domagk D, Oppong KW, Aabakken L et al. Performance measures for ERCP and endoscopic ultrasound: a European Society of Gastrointestinal Endoscopy (ESGE) Quality Improvement Initiative. Endoscopy 2018; 50: 1116-1127 